\title{
The Foreign Exchange Risk Premium A Disaggregate Approach
}

Dionysios Chionis, (Email: dichionis@econ.uth.gr), University of Thessaly, Greece Nicolaos Kyriazis, University of Thessaly, Greece

\begin{abstract}
This paper re-examines the issue of the existence of a time-varying risk premia in the three foreign exchange markets. By using the theoretical framework developed by Domowitz and Hakkio it relates the risk premium in the foreign exchange market with the heterogeneity across the market participants. The empirical research using a disaggregate survey data base support the importance is supportive of the existence of time-varying risk premia for the British Pound, German Mark and Japanese Yen exchange rates. In particular, we demonstrate that consensus measures of the risk premium mask the existence because of the importance of heterogenous expectations.
\end{abstract}

\section{Introduction}

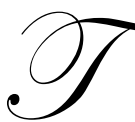

he debate regarding the rationality of agents' expectations and the informational efficiency of foreign exchange markets continues to be an issue of central concern to academic and policy makers. We will test propositions relating to these hypotheses by analyzing survey data from some of the major currencies (German mark, Japan yen and British pound) relative to the United States dollar. The contribution of this work is that we implement statistical and econometric tests on an individual agent basis rather than adopting the pooling technique of previous researchers [Dominguez (1986), Frankel and Froot (1990), MacDonald and Torrance (1990)] who assess the statistical properties of the forecasting mean. For this reason we will use a data set which is generated by Consensus Forecasts of London.

Since October 1989 Consensus Forecasts have surveyed and published the exchange rate forecasts of economists, foreign exchange dealers and executives in over 150 companies and institutions in the G-7 nations. The companies surveyed are mainly commercial and investment banks, but industrial corporations and forecasting agencies are also polled. The responders return a fax on the first Monday of each month containing their point forecasts of dollar-sterling, Deutschmark-dollar and yen-dollar exchange rates three and twelve calendar months ahead. Since the response rate is less than perfect, in the work which follows we constrain our analyses to a subset of the total panel (in particular, a total panel of 60 individuals, approximately).

Additionally, we have estimated the properties of the mean for the three different groups of activities consisting our data set. MBANK stands for the mean of the banks MSEC and MINDUST, stand for the mean of securities companies, and industries, respectively. The mean across forecasters located in the same nation will be referred to as MUK, MGER, MFRA, MITA, MJAP, MUSA, and MCAN. In the rest of the paper we will refer to the mean across countries as a country mean, and the mean ranked with the criterion of the type of activities will be named as the group mean. At the end, it should be noted that in addition to the survey data we collected data on spot and forward exchange rates from Datastream International. The outline of this work is as follows.

A review of previous work is provided in section 2. We will derive the survey-based risk-premium in section 3. This model is a version of the cash-in-advance monetary model providing a foreign exchange risk

Readers with comments or questions are encouraged to contact the authors via email. 
premium which depends on the conditional variance of domestic and foreign money supply, augmented by the existing heterogeneity among the market participants. By using the disaggregate data set and an ARCH class of models we assess, in section 4, the performance ability of the previously developed model. Section 5 concludes and at the end, section 6 makes suggestions for future research.

\section{Previous empirical and theoretical work}

A large number of researchers [for a review see Engle (1995)] have tested the Efficient Market Hypothesis using a variety of currencies and time periods and report results which are unfavorable to the unbiasedness and orthogonality hypotheses. In the light of this research a number of researchers expand the investigation regarding the rationality of agents' expectations and the informational efficiency of the foreign exchange market using survey data. A number of papers using survey data include Dominguez (1986), Froot and Frankel (1989), Ito (1990), Allen and Taylor (1990), MacDonald and Torrance (1990), Chinn and Frankel (1994). This body of empirical work indicates that throughout the 1980's and 1990's we can reject the hypothesis of market efficiency for the foreign exchange markets. Another research element from this literature is that both irrationality and time-varying risk premia seem to be responsible for the rejection.

Another branch of the literature has examined the theoretical and empirical models which can derive the risk premium. There are a number of models that generate a time-varying risk premium. Between them, particular attention must be paid to the equilibrium, dynamic, optimizing models of asset pricing. Lucas (1978) presents such a model in an international context. The subsequent theoretical research has been motivated by the operationalising of the Euler conditions in the cash in advance model. Although the starting point remain the optimization of the first order condition there are three different approaches that have been developed. The CAPM/latent variable approach Hodrick (1987) and the risk free premium [inter alia Hodrick Srivastava (1986), Campell and Clarida (1987)] are included in the first two categories.

The most popular way of implementing the first order conditions has been the third category, the Autoregressive Conditional Heteroskedasticity (ARCH) framework, originally proposed by Engle (1982). A growing body of researchers have used the ARCH-M class of models suggested by Engle, Lilien and Robins (1987). According to this the conditional mean of the foreign exchange changes is an explicit function of the conditional variance of the forecast errors. In this model an increase in the conditional variance will be associated with an increase or an decrease in the conditional mean depending on the sign of the partial derivative of the function with respect to the variance. Domowitz and Hakkio (1985) were the first to apply this class to the forward exchange market. The basic idea in this model, as in many theories in financial economics, is the use of a measure of risk as an explanatory variable. To the extent that the conditional variance of an error term is a measure of risk it seems logical that the variance should enter the regression function as a measure of the risk premium. The authors use five currencies and report rather negative results. Kaminsky and Peruga (1990) reestimate the model of Domowitz and Hakkio in a multivariate context and they argue that the negative findings is a reflection of the failure to take into account properly exchange market interdependencies. In the same context several authors [McCurdy and Morgan (1987), (1988) Diebold and Pauly (1987), Lee (1988), Ballie and Bollerslev (1990)] suggest that the weak results might be due to the fact that the univariate ARCH-M's conditional variance being poor proxies for risk.

Before proposing another research path for modeling the risk premium in the ARCH context, however, we first of all conduct some empirical tests of our survey data set.

\section{Time series properties and some empirical regularities}

In this section we consider the time series properties of the forward premium and the survey based variables; i.e. the expected exchange rate changes and the survey forecast error. Although the scope of this work is the derivation of conclusions regarding the time series properties of individual participants in the foreign exchange market, for matter of convenience we present, in tables 1-7, the properties related to the means. 
The Augmented Dickey Fuller tests applied to the spot rates are consistent with previous findings that the spot rate is a nonstationary process. Further, by applying the same test to the spot rate changes: $\Delta \mathrm{s}^{\mathrm{e}}{ }_{\mathrm{t}+\mathrm{k}}=\mathrm{s}_{\mathrm{t}}-\mathrm{s}_{\mathrm{t}+\mathrm{k}}^{\mathrm{e}}$ where $\mathrm{s}_{\mathrm{t}+\mathrm{k}}^{\mathrm{e}}$ is the survey based rate, corresponds to either the group/country means, or to the individual forecasts, we conclude that the spot rate is a difference stationary process in each case ${ }^{1}$.

It should be noted that although the degree of integration of the forward premium is an issue that it is not yet settled in the literature in the present work, by applying the ADF we can reject the null of a unit root for the forward discount across the three currencies ${ }^{2}$.

Table 1 panels A and B provide summary statistics for the expected exchange rate changes, the survey errors and the forward premium for the three currencies. The expected exchange rate changes and the survey errors are further decomposed taking the mean per country and the mean per activity. Before considering the time series properties of the financial series in question, we have to note that the literature using the assumption of rational expectations has concluded the following regularities: 1. Exchange rates are many times more variable than the forward premium. In fact $\sigma_{\mathrm{k}}\left(\Delta \mathrm{s}_{\mathrm{t}+\mathrm{k}}\right)>\sigma_{\mathrm{f}}\left(\mathrm{fp}_{\mathrm{t}+\mathrm{k}}\right)$ and consequently the variance of $\mathrm{E}_{\mathrm{t}}\left(\mathrm{s}_{\mathrm{t}+1}\right)-\mathrm{s}_{\mathrm{t}}$ is too large to be explained in the conventional models by the forward premium; 2. Forward premia and exchange rate changes exhibit marked positive serial dependence in their second moments and substantial leptokyrtosis.

Table 1

Time Series Properties Of The Aggregate Mean

\begin{tabular}{|c|c|c|c|}
\hline & $\underset{\Delta \mathbf{s}_{t+3}^{e_{t}}}{P A N E}$ & $\begin{array}{c}D M \\
\mathbf{f p}_{\mathrm{t}+3}\end{array}$ & $\mathbf{s}_{t+3^{-}}^{\mathrm{e}} \mathbf{s}_{\mathrm{t+}}$ \\
\hline Mean & 0.005 & -0.002 & 0.0011 \\
\hline$\sigma^{2}$ & $8.7 \mathrm{e}-005$ & $8.8 \mathrm{e}-006$ & 0.0009 \\
\hline $\mathrm{Ku}$ & $\begin{array}{c}-0.48 \\
(0.44)\end{array}$ & $\begin{array}{c}-0.59 \\
(0.356)\end{array}$ & $\begin{array}{c}0.907 \\
(0.157)\end{array}$ \\
\hline $\mathrm{Q}_{16}$ & $\begin{array}{c}126 \\
(0.000)\end{array}$ & $\begin{array}{c}231 \\
(0.00)\end{array}$ & $\begin{array}{c}85.85 \\
(0.000)\end{array}$ \\
\hline
\end{tabular}

\begin{tabular}{|c|c|c|c|}
\hline & $\underset{\Delta \mathbf{s}_{t+3}^{e_{t+3}}}{P A N}$ & $\begin{array}{l}J Y \\
\mathbf{f p}_{\mathrm{t}+3}\end{array}$ & $s_{t+3^{-}}^{e} s_{t+3}$ \\
\hline Mean & 0.0004 & -0.0006 & 0.0088 \\
\hline$\sigma^{2}$ & 7.7e-005 & $3.4 \mathrm{e}-006$ & 0.0006 \\
\hline $\mathrm{Ku}$ & 0.148 & -0.78 & 0.930 \\
\hline & $(0.817)$ & $(0.223)$ & $(0.046)$ \\
\hline $\mathrm{Q}_{16}$ & $\begin{array}{c}173 \\
(0.000)\end{array}$ & $\begin{array}{c}94 \\
(0.000)\end{array}$ & $\begin{array}{c}71.6 \\
(0.000)\end{array}$ \\
\hline
\end{tabular}

\begin{tabular}{lccc} 
& \multicolumn{4}{c}{$\boldsymbol{P A N E L} \boldsymbol{C}: \boldsymbol{B P}$} & \\
& $\Delta \mathbf{s}_{\mathbf{t}+\mathbf{3}}^{\mathbf{e}^{2}}$ & $\mathbf{f p}_{\mathbf{t + 3}}$ & $\mathbf{s}_{\mathbf{t + 3}}^{\mathbf{e}}-\mathbf{s}_{\mathbf{t}+3}$ \\
Mean & -0.004 & -0.004 & 0.001 \\
$\sigma^{2}$ & $4.7 \mathrm{e}-005$ & $9.5 \mathrm{e}-006$ & 0.0009 \\
$\mathrm{Ku}$ & -0.60 & 2.01 & 3.29 \\
& $(0.34)$ & $(0.001)$ & $(0.000)$ \\
$\mathrm{Q}_{16}$ & 22.21 & 137 & 60.63 \\
& $(0.316)$ & $(0.00)$ & $(0.000)$
\end{tabular}

\footnotetext{
* describes a test of the null hypothesis that the population kurtosis is zero. This is the population value if the series is i.i.d. Normal

$\sigma^{2}$ indicates the variance

$Q_{16}$ :indicates the Ljung-Box $Q$-Statistics for the 16 correlation coefficients into the parentheses are the level of significance
} 
By examining the time series properties of the aggregate mean, several features deserve comment.

In accordance with the previous findings using the rational expectations literature the unconditional variance of the exchange rate change is many times more variable than the variance of the forward premium. This is cleaner in the cases of the group and country means. Further, both for the individual markets and for the means the unconditional variance of exchange rate changes is large relative to the unconditional variance of the average. The forward premium exhibits all the stylized properties; i.e. presents substantial serial correlation and heteroskedasticity. The fourth moments of both variables suggest that these distributions deviate from normality. In most cases we can reject the null hypothesis of a normal distribution. Similarly, an examination of the unconditional distribution of the survey error series indicates evidence of time variation in the conditional variances. The unusually high variance of the forward premium and the significant serial correlation are consistent with the large body of empirical work which indicates that throughout the late 1980's and early 90's nominal profits from speculation in forward contracts on the US dollar were highly volatile but also displayed a predictable component which was itself volatile and serially correlated.

Common phenomenon in the above series is the substantial serial correlation apparent in the expected profits and the survey errors. The very strong persistence, especially in the expected changes, can be partly attributed to the fact that the three months period exceeds the sampling frequency of our survey data and one should expect some serial correlation to appear even though the true series is not predictable using the time $t$ information set ${ }^{3}$.

Table 2

DM 3-Months Forecasts

\begin{tabular}{|c|c|c|c|c|c|c|c|}
\hline \multirow{3}{*}{$\begin{array}{l}\text { Mean } \\
\sigma^{2}\end{array}$} & \multicolumn{7}{|c|}{ VEL A : Expected exchang } \\
\hline & $\frac{120 \pi}{0.006}$ & $\frac{\mathrm{NICAN}}{0.0008}$ & $\frac{0.007}{0.11}$ & 0.006 & $\frac{100114}{0.004}$ & $\frac{\frac{\text { VIJAP }}{0.003}}{}$ & $\frac{1 \mathrm{NOSA}}{0.004}$ \\
\hline & 0.00012 & 0.0001 & $9.52 \mathrm{e}-005$ & 0.0001 & 0.0001 & 0.0001 & $7.83 \mathrm{e}-005$ \\
\hline $\mathrm{Ku}$ & $\begin{array}{l}-0.441 \\
(0.491)\end{array}$ & $\begin{array}{c}9.12 \\
(0.000)\end{array}$ & $\begin{array}{c}-0.616 \\
(0.336)\end{array}$ & $\begin{array}{c}-0.22 \\
(0.730)\end{array}$ & $\begin{array}{l}-0.377 \\
(0.556)\end{array}$ & $\begin{array}{c}0.527 \\
(0.410)\end{array}$ & $\begin{array}{c}-0.533 \\
(0.40)\end{array}$ \\
\hline $\mathrm{Q}_{16}$ & $\begin{array}{c}181 \\
(0.000)\end{array}$ & $\begin{array}{c}18.93 \\
(0.217)\end{array}$ & $\begin{array}{c}87 \\
(0.000)\end{array}$ & $\begin{array}{c}123 \\
(0.000)\end{array}$ & $\begin{array}{c}140 \\
(0.000)\end{array}$ & $\begin{array}{c}41.8 \\
(0.000)\end{array}$ & $\begin{array}{c}34.8 \\
(0.005)\end{array}$ \\
\hline \multicolumn{8}{|c|}{ PANEL B : Survey error per country mean } \\
\hline & $\underline{\text { MUK }}$ & MCAN & MFRA & MGER & MITA & MJAPAN & $\underline{\text { MUSA }}$ \\
\hline Mean & 0.0126 & 0.007 & 0.0141 & 0.010 & 0.010 & 0.009 & 0.011 \\
\hline$\sigma^{2}$ & 0.0009 & 0.0009 & 0.0009 & 0.001 & 0.001 & 0.0009 & 0.0009 \\
\hline $\mathrm{ku}$ & $\begin{array}{c}0.757 \\
(0.237)\end{array}$ & $\begin{array}{c}042 \\
(0.504)\end{array}$ & $\begin{array}{c}0.87 \\
(0.171)\end{array}$ & $\begin{array}{c}1.11 \\
(0.081)\end{array}$ & $\begin{array}{c}0.94 \\
(0.142)\end{array}$ & $\begin{array}{c}0.702 \\
(0.273)\end{array}$ & $\begin{array}{c}0.709 \\
(0.273)\end{array}$ \\
\hline $\mathrm{Q}_{16}$ & $\begin{array}{c}84 \\
(0.000)\end{array}$ & $\begin{array}{l}177.5 \\
(0.217)\end{array}$ & $\begin{array}{c}90.3 \\
(0.000)\end{array}$ & $\begin{array}{c}83.4 \\
(0.000)\end{array}$ & $\begin{array}{c}88.6 \\
(0.000)\end{array}$ & $\begin{array}{c}78.5 \\
(0.000)\end{array}$ & $\begin{array}{c}85.6 \\
(0.005)\end{array}$ \\
\hline
\end{tabular}

Table 3

DM 3-Months Forecasts

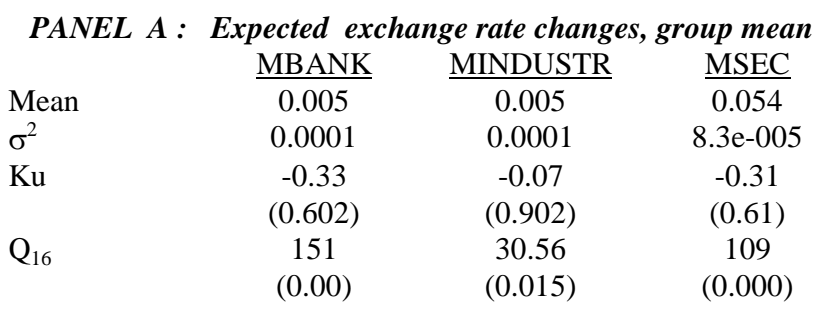


PANEL B : Survey errors, group mean (Table 3 continued)

\begin{tabular}{|c|c|c|c|}
\hline & MBANKS & MINDUSTR & MSEC \\
\hline Mean & 0.011 & 0.012 & $\overline{0.011}$ \\
\hline$\sigma^{2}$ & 0.0009 & 0.0008 & 0.0009 \\
\hline $\mathrm{ku}$ & 1.20 & 0.368 & 0.748 \\
\hline & $(0.061)$ & $(0.565)$ & $(0.243)$ \\
\hline $\mathrm{Q}_{16}$ & $\begin{array}{c}87.4 \\
(0.00)\end{array}$ & $\begin{array}{c}89 \\
(0.000)\end{array}$ & $\begin{array}{c}84.7 \\
(0.000)\end{array}$ \\
\hline
\end{tabular}

Table 4

JY 3-Months Forecasts

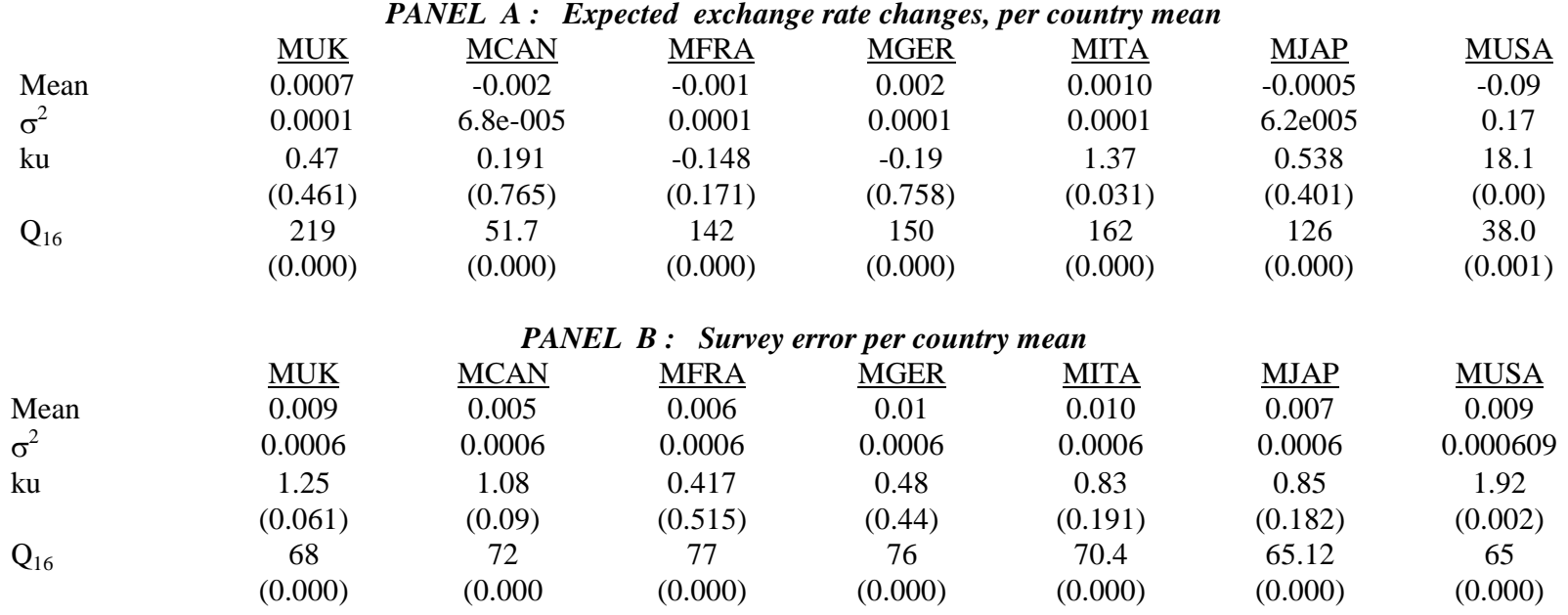

Table 5

JY 3-Months Forecasts

PANEL A : Expected exchange rate changes, group mean

\begin{tabular}{|c|c|c|c|}
\hline & MBANK & MINDUST & MSEC \\
\hline Mean & 0.005 & 0.001 & $-\overline{0.0003}$ \\
\hline$\sigma^{2}$ & 0.0003 & 0.0001 & $5.2 \mathrm{e}-005$ \\
\hline $\mathrm{ku}$ & -0.737 & 96.7 & 0.49 \\
\hline & $(0.274)$ & (0.08) & $(0.44)$ \\
\hline $\mathrm{Q}_{16}$ & $\begin{array}{c}56 \\
(0.00)\end{array}$ & $\begin{array}{c}96 \\
(0.000)\end{array}$ & $\begin{array}{c}98.16 \\
(0.000)\end{array}$ \\
\hline
\end{tabular}

\begin{tabular}{lccc}
\multicolumn{4}{c}{ PANEL $\boldsymbol{B}:$ Survey errors, group mean } \\
MBANK & MINDUST & $\underline{\text { MSEC }}$ \\
Mean & O.013 & 0.009 & 0.008 \\
$\sigma^{2}$ & 0.0007 & 0.0006 & 0.0005 \\
$\mathrm{ku}$ & -0.05 & -0.7 & 1.15 \\
& $(0.937)$ & $(0.219)$ & $(0.071)$ \\
$\mathrm{Q}_{16}$ & 56 & 66 & 68 \\
& $(0.00)$ & $(0.015)$ & $(0.000)$
\end{tabular}


Table 6

BP 3-Months Forecasts

\begin{tabular}{|c|c|c|c|c|c|c|c|}
\hline \multirow{3}{*}{$\begin{array}{l}\text { Mean } \\
\sigma^{2}\end{array}$} & MUK & $\begin{array}{l}\text { NEL A : } \\
\text { MCAN }\end{array}$ & MFRA & MGER & MITA & MJAP & MUSA \\
\hline & $-\overline{0.0047}$ & $\overline{-0.002}$ & $\overline{-0.006}$ & $\overline{-0.006}$ & $\overline{-0.218}$ & $\overline{-0.11}$ & $\overline{-0.007}$ \\
\hline & $6.5 \mathrm{e}-005$ & $5.7 \mathrm{e}-005$ & $6.6 \mathrm{e}-005$ & $6.2 \mathrm{e}-005$ & 0.001 & 0.0001 & $8.6 e-005$ \\
\hline \multirow[t]{2}{*}{$\mathrm{ku}$} & -0.55 & -0.28 & -0.15 & -0.55 & -1.06 & 5.4 & 0.11 \\
\hline & $(0.38)$ & (0.66) & $(0.808)$ & $(0.38)$ & $(0.096)$ & $(0.000)$ & $(0.86)$ \\
\hline \multirow[t]{2}{*}{$\mathrm{Q}_{16}$} & 42.9 & 29.7 & 33.9 & 29.9 & 225 & 16.8 & 18.33 \\
\hline & $(0.000)$ & $(0.019)$ & $(0.005)$ & $(0.018)$ & $(0.000)$ & $(0.397)$ & $(0.304)$ \\
\hline \multicolumn{8}{|c|}{ PANEL B : Survey error per country mean } \\
\hline & $\underline{\text { MUK }}$ & MCAN & $\underline{\text { MFRA }}$ & $\underline{\text { MGER }}$ & $\underline{\text { MITA }}$ & $\underline{\text { MJAP }}$ & $\underline{\text { MUSA }}$ \\
\hline Mean & -0.006 & -0.0044 & -0.008 & -0.007 & $-0 . .007$ & -0.0005 & -0.0088 \\
\hline$\sigma^{2}$ & 0.0009 & 0.001 & 0.0009 & 0.0009 & 0.001 & 0.001 & 0.0008 \\
\hline \multirow[t]{2}{*}{$\mathrm{ku}$} & 2.23 & 2.77 & 2.00 & 2.00 & -1.82 & 2.1 & 2.2 \\
\hline & $(0.0004)$ & $(0.00)$ & $(0.001)$ & $(0.01)$ & $(0.004)$ & $(0.000)$ & $(0.0006)$ \\
\hline \multirow[t]{2}{*}{$\mathrm{Q}_{16}$} & 71.88 & 72.8 & 78.8 & 79.9 & 89.4 & 72.3 & 73.9 \\
\hline & $(0.000)$ & $(0.000)$ & $(0.000)$ & $(0.000)$ & $(0.000)$ & $(0.000)$ & (0.000) \\
\hline
\end{tabular}

Table 7

BP 3-Months Forecasts

\begin{tabular}{lccc}
\multicolumn{1}{c}{ PANEL A : } & $\begin{array}{c}\text { Expected exchange rate changes, group mean } \\
\text { MBANK }\end{array}$ & MINDUST & $\underline{\text { MSEC }}$ \\
Mean & 0.003 & -0.0029 & -0.003 \\
$\sigma^{2}$ & 0.0002 & 0.0001 & $5.0 \mathrm{e}-005$ \\
$\mathrm{ku}$ & 2.52 & 1.16 & -0.58 \\
& $(0.0001)$ & $(0.068)$ & $(0.365)$ \\
$\mathrm{Q}_{16}$ & 31.8 & 35.3 & 18.90 \\
& $(0.010)$ & $(0.003)$ & $(0.273)$
\end{tabular}

\begin{tabular}{lccc}
\multicolumn{4}{c}{ PANEL $\boldsymbol{B}$ : Survey errors, group mean } \\
MBANK & MINDUST & $\underline{\text { MSEC }}$ \\
Mean & -0.007 & -0.004 & -0.005 \\
$\sigma^{2}$ & 0.0009 & 0.0009 & 0.0009 \\
$\mathrm{ku}$ & 2.26 & 1.4 & 2.35 \\
& $(0.0004)$ & $(0.02)$ & $(0.000)$ \\
$\mathrm{Q}_{16}$ & 79.2 & 83 & 75.85 \\
& $(0.00)$ & $(0.000)$ & $(0.000)$
\end{tabular}

From estimating the empirical properties we can derive some more useful conclusions for the forecasting behavior of the individuals. The largest average forecast errors were recorded by the banking sector and by the institutions located in the U.K. and Italy. The forecasting behavior for the DM and JY of the industrial sector present similarities with this of the banking sector while in the case of BP the similarities can be traced between the industry sector and the security industry. Common forecasting patterns as regard the direction of the spot changes turn out for DM and BP across countries. In the case of the JY the forecasts across countries seem to be differentiated. Close inspection of the individual series indicates the existence of heterogeneity among the market participants, confirming the results of the previous chapter. We further examine the degree of heterogeneity in the two different groups. Under the assumption that the degree of heterogeneity is expressed by the standard deviation among the market participants we estimate the cross correlation between the standard deviation of the banks and the security industry. For all currencies the estimated Q-stat seems to reject strongly the null hypothesis of statistically significant cross correlation. 
At the end, it should be noted that the estimation of the survey-data properties indicate the seriousness of the answers. One of the common criticisms of the use of the survey expectation data is that respondents to the questionnaire may not be serious in answering questions. The consistency of the properties of expected exchange rate changes and the forecast errors with these of the rational expectation data is an additional indication for the usefulness of the survey data ${ }^{4}$.

\section{A Model of the Risk Premium with Heterogeneous Expectations}

Typically, in writing models of the foreign exchange premium it is assumed that all agents are identical (representative agent models), and hence the equilibrium relationships are derived for a representative agent. ${ }^{5}$ However, from the results derived by Ito (1990) and Chionis and MacDonald (1997) this does not seem to be an appropriate assumption for the foreign exchange market: in forecasting the exchange rate, agents seem to deviate systematically from each other due to both individual and idionsycratic effects. Therefore, in this section we derive a model of the risk premium which is consistent with using survey data to measure the premium and, in particular, captures the evident heterogeneity of such data. Our model yields an exchange rate equation with a time-varying risk premium that is not only a function of the conditional variance of domestic and foreign money, as in Domowitz and Hakkio, but also incorporates additional terms which arise from the forecasting process augmented by a term which indicates the deviation of an individual's forecasting of future money demand from the rational forecaster plus a term which accounts for the disturbances created by noise traders.

The general structure of the model consists of two countries $(U, E)$ two goods $(x, y)$ and two monies $(M, N)$. Consumers in country $U$ receive an endowment $\xi_{t}$ of good $x$, and nothing of good $y$; consumers in E receive nothing of good $x$ and an endowment $\eta_{t}$ of good $y$. Agents of each country demand both $\mathrm{M}$ and $\mathrm{N}$, the demand being motivated by a cash-in-advance constraint. ${ }^{6}$ The current period utility function, which is the same for all traders, is assumed to be of Cobb-Douglas form: $U(x, y)=A x^{a} y^{1-b}$. Agents maximize an intertemporal utility function of the form $\sum_{\mathrm{t}=0}^{\infty} \beta^{t} U\left(x_{t}, y_{t}\right)$, subject to a standard budget constraint. This constraint is of the form for the period $\mathrm{t}$ to $\mathrm{t}+1$ :

$a_{t+1}=r_{t}\left(a_{t}+y_{t}-c_{t}\right)$

where $a_{t}$ denotes real wealth, $y_{t}$ denotes labour income, $y_{t}-c_{t}$ denotes savings from labour income and $r_{t}$ denotes one plus real interest rate.

The endowments are assumed to follow first-order Markov processes:

$\ln \xi_{t}=\rho_{1} \ln \xi_{t-1}+u_{1 t} \quad$ and $\ln \eta_{t}=\rho_{2} \ln \eta_{t-1}+u_{2 t}$ with $\boldsymbol{u} \sim N\left(\boldsymbol{O}, \boldsymbol{H}_{t}\right) \quad \boldsymbol{O}^{\prime}=(0,0)$ and $\boldsymbol{H}_{t}=\operatorname{diag}\left(h_{1,}, h_{2 t}\right)$

The nominal prices of the good $y$ and $x$ are $p_{x}=M / \xi$ and $p_{y}=N / \eta \quad$ (also, $p_{y}$ ' denotes the price of $y$ in $x$-units). In equilibrium the exchange rate is given by a purchasing power parity formula:

$$
S_{t}=p_{x} p_{y}^{\prime} / p_{y}=\left(M \eta p_{y}^{\prime}\right) / \xi_{t} N
$$

If we equilibrate the relative price of $y$ to the MRS we get:

$$
p_{y}^{\prime}=[(1-a) / a] \xi \eta^{-1},
$$

and by making the substitution into the exchange rate equation we get:

$$
S_{t}=[(1-a) / a]\left(M_{t} / N_{t}\right)
$$


Without loss of generality we can assume that the equilibrium exchange rate in time t, $S_{t}$, is known to both the smart and noise traders ${ }^{7}$. Then the forward rate is given by

$$
F_{t}=S_{t} E_{t}^{M}\left[Q_{t+1}^{N}\right] / E_{t}^{M}\left[Q_{t+1}^{M}\right]
$$

where: $\quad Q_{t+1}{ }^{N}, Q_{t+1}{ }^{M}$ are the intertemporal marginal rates of substitutions for two monies and $E_{t}^{M}$ denotes the market's expectations of $Q^{N}{ }_{t+1}$ and $Q^{M}{ }_{t+1}$ which may contain both rational and non-rational elements, and

$$
\begin{aligned}
& Q_{t+1}^{N}=\beta\left(\xi_{t+1} / \eta_{t+1}\right)^{a} /\left(N_{t+1} / \eta_{t+1}\right) /\left(\xi_{t} / \eta_{t}\right)^{a} /\left(N_{t} / \eta_{t}\right), \\
& Q_{t+1}^{M}=\beta\left(\eta_{t+1} / \xi_{t+1}\right)^{I-a} /\left(M_{t+1} / \xi_{t+1}\right) /\left(\eta_{t} / \xi_{t}\right)^{l-a} /\left(M_{t} / \xi_{t}\right),
\end{aligned}
$$

Following the conceptual framework of noise trading proposed by DeLong et al. (1990) we allow for two categories of individuals. The first category utilizes a sophisticated forecasting method. Each investor in this group is assumed to use the same first-order Markov process to forecast money demand in the domestic and foreign country. That is:

$\ln M_{t}=\gamma_{1} \ln M_{t-1}+u_{3 t}^{s}, \quad \ln N_{t}=\gamma_{2} \ln N_{t-1}+u_{4 t}^{s}, \quad u_{3 t}^{s} \sim\left(0, h_{33 t}\right) \quad$ and $u_{4 t}^{s} \sim\left(0, h_{44 t}\right)$,

The second category of trader exploits a noise trading process. In this case agent $\mathrm{i}$ in forecasting future money demand uses an idiosynchratic model, assigning a different coefficient in the Markov process. In this case the money demand takes the form:

$\ln M_{i, t}=\gamma_{1, i} \ln M_{t-1}+u_{3, t, i}^{n}, \ln N_{i, t}=\gamma_{2, i} \ln N_{t-1}+u_{4, t, i}^{n}, \quad u_{3, t, i}^{n} \sim\left(\boldsymbol{\mu}_{3, i, t}, h_{33, t, i}\right)$ and $u_{4, t, i}^{n} \sim\left(\boldsymbol{\mu}_{4, i, t}, h_{44, t, i}\right)$

Since the process of logmoney is often thought of containing a unit root we can further assume that $\Sigma \gamma_{1 i}>1$ and $\Sigma \gamma_{2 \mathrm{i}}>1$. With these assumptions it is not affected the long memory process of the logmoney.

In order to derive the market expectation we further assume that the expectation of the intertemporal marginal rates of substitution for the two currencies are derived by the market as a weighted average of the expectations of smart investors and noise traders. That is, the market assigns a proportion $\omega$ to the expectations derived by the smart investors and $(1-\omega)$ to the expectations derived by the noise traders. Then relation (7) becomes:

$$
F_{t}=S_{t} \frac{\omega E_{t}^{S}\left[Q_{t+1}^{N}\right]+(1-\omega) Z_{t}^{N}\left[Q_{i, t+1}^{N}\right]}{\omega E_{t}^{S}\left[Q_{t+1}^{M}\right]+(1-\omega) Z_{t}^{N}\left[Q_{i, t+1}^{M}\right]},
$$

where $E_{t}^{s}$ is the conditional expectations operator (i.e. $E_{t}^{s}=E\left[. / I_{t}\right]$ ) of the smart money and $Z_{t}^{N}$ is the subjective expectation of the noise traders. Alternatively $\left(6^{\prime}\right)$ may be expressed in logs as:

$\ln F_{t}=\ln [(1-a) / a]+\ln M_{t}+\ln N_{t}+\ln \left\{\omega E_{t}^{S}\left[Q^{N}{ }_{t+1}\right]+(1-\omega) Z_{t}^{N}\left[Q^{N}{ }_{i, t+1}\right]\right\}-\ln \left\{\omega E_{t}^{S}\left[Q^{M}{ }_{t+1}\right]-(1-\omega) Z_{t}^{N}\left[Q^{M}{ }_{i, t+1}\right]\right\}$.

where:

$$
\ln Q_{t+1}^{N}=\ln \beta-(1-\alpha)\left(1-\rho_{2}\right) \ln \eta_{t}-\alpha\left(1-\rho_{1}\right) \ln \xi_{t}+\left(1-\gamma_{2}\right) \ln N_{t}+\left[(\alpha-1)^{2} / 2\right] h_{22, t+1}+\left(\alpha^{2} / 2\right) h_{11, t+1}+h_{44, t+1}
$$


$\left.\ln Q_{t+1}^{M}=\ln \beta-\alpha\left(1-\rho_{1}\right) \ln \xi_{t}-(1-\alpha)\left(1-\rho_{2}\right) \ln \eta_{t}+\left(1-\gamma_{1}\right) \ln M_{t}+\left[(\alpha)^{2} / 2\right] h_{1, l t+1}+\left[(\alpha-1)^{2} / 2\right)\right] h_{22, t+1} h_{33, t+1}$

$$
\begin{aligned}
\ln Q_{i, t+1}^{N} & =\ln \beta-(1-\alpha)\left(1-\rho_{2, i}\right) \ln \eta_{t}-\alpha\left(1-\rho_{1, i}\right) \ln \xi_{t}+\left(1-\gamma_{2, i}\right) \ln N_{i, t}+\left[(\alpha-1)^{2} / 2\right] h_{22, i, t+1}+\left(\alpha^{2} / 2\right) h_{11, i, t+1} h_{44, i, t+1}+\mu_{4, i, t+1,} \\
\ln Q_{i, t+1}^{M} & \left.=\ln \beta-\alpha\left(1-\rho_{1, i}\right) \ln \xi_{t}-(1-\alpha)\left(1-\rho_{2, i}\right) \ln \eta_{t}+\left(1-\gamma_{1, i}\right) \ln M_{i, t}+\left[(\alpha)^{2} / 2\right] h_{11, i, t+1}+\left[(\alpha-1)^{2} / 2\right)\right] h_{22, i, t+1}+h_{33, i, t+1} \\
& +\mu_{3, i, t+1 .}
\end{aligned}
$$

On making the relevant substitutions, the market's forward rate may be expressed as:

$\ln F_{t}=\ln S_{t}+\ln [(1-a) / a]+\ln M_{t}\left[1-\omega\left(1-\gamma_{1}\right)\right]-\ln N_{t}\left[1-\omega\left(1-\gamma_{2}\right)\right]+\omega\left[-1 / 2 h_{33, t+1}+1 / 2 h_{44, t+1}\right]+(1-\omega)\left\{\left(1-\gamma_{2, i}\right) \ln N_{i, t}-\right.$
$\left.\left(1-\gamma_{1, i}\right) \ln M_{i, t}-1 / 2 h_{33, i, t+1}+1 / 2 h_{44, i, t+1}-\mu_{3, i, t+1}+\mu_{4, i, t+1}\right\}$.

The future spot rate derived by the sophisticated trader is given by:

$E_{t}^{S} \ln S_{t+1}=\ln [(1-a) / a]+E_{t}^{S} \ln M_{t+1}-E_{t}^{S} \ln N_{t+1}=\ln [(1-a) / a]+\gamma_{1} \ln M_{t+1}-\gamma_{2} \ln N_{t+1}$

This is common for each individual included in the first category of forecasters. Subtracting relation (10) from (11) we may derive the risk premium which arises for the sophisticated process as:

$$
\begin{aligned}
\ln F_{t}- & E_{t} \ln S_{t+1}^{S}=\ln S_{t}+\ln [(1-a) / a]+\ln M_{t}\left[1-\omega\left(1-\gamma_{1}\right)\right]-\ln N_{t}\left[1-\omega\left(1-\gamma_{2}\right)\right]+\omega\left[1 / 2 h_{33, t+1}+1 / 2 h_{44, t+1}\right]+(1- \\
& \omega)\left\{\left(1-\gamma_{2, i}\right) \ln N_{i, t}-\left(1-\gamma_{1, i}\right) \ln M_{i, t}-1 / 2 h_{33, i, t+1}+1 / 2 h_{44, i, t+1}-\mu_{3, i, t+1}+\mu_{4, i, t+1}\right\}-\left\{\ln [(a-1) / a]+\gamma_{1} \ln M_{t+1}-\gamma_{2}\right. \\
& \left.\ln N_{t+1}\right\}
\end{aligned}
$$

or

$$
\begin{aligned}
& \lambda_{t}^{r e}=\ln F_{t}-E_{t}^{s} \ln S_{t+1}=\omega\left\{\left[E_{t}^{S} \ln M_{t+1}-E_{t}^{S} \ln N_{t+1}\right]-\left[Z_{t}^{N} \ln M_{i, t+1}-Z_{t}^{N} \ln N_{i, t+1}\right]\right\}+\omega / 2 \\
& \left(h_{33, t+1}-h_{44, t+1}\right)
\end{aligned}
$$

where $Z_{t}^{N}$ denotes the subjective expectation operator of the noise trader and $E_{t}$ denotes the conditional expectations operator of the smart investor.

According to (12), the risk premium of a smart investor depends upon the conditional variance, augmented by additional terms which take into account the deviation of the expectation of the noise trader from the rational trader weighted by the weight assigned by the market to the noise trader. It should be noted that in the case where the market deriving the ratio of intertemporal rate of substitution uses only the smart investors' expectation, then $\omega=1$ and (12) will degenerate to the risk premium derived by Domowitz and Hakkio.

For the noise trader, the derivation of the future spot rate differs from (11) because each individual assigns a different coefficient to the Markov process in the money market. Thus we have:

$$
Z_{t}^{N}\left[S_{i, t+1}\right]=[(1-a) / a]\left(Z_{t}^{N}\left[M_{i, t+1}\right] / Z_{t}^{N}\left[N_{i, t+1}\right]\right)
$$

Re-expressing (13) in logs we have:

$$
Z_{t}^{N} \ln S_{i, t+1}=\ln [(a-1) / a]+Z_{t}^{N} \ln M_{i, t+1}-Z_{t}^{N} \ln N_{i, t+1}
$$

and given the Markov structure $(8)^{8}$ we have

$$
\left.Z_{t}^{N} \ln S_{i, t+1}=\ln (1-a) / a\right]+\gamma_{1 i} \ln M_{i, t}-\mu_{3, i, t+1^{-}}-\gamma_{2 i} \ln N_{i t}-\mu_{4, i, t+1},
$$


On subtracting (10) from (14) we obtain the risk premium for each individual using the noise process as:

$\ln F_{t}-\ln Z_{t}^{N} \ln S_{t, t+1}=\omega\left[\left(E_{t}^{S} \ln N_{t+1}-E_{t}{ }^{S} \ln M_{t+1}\right)\right]+(1-\omega)\left(Z_{t}^{N} \ln N_{i, t+1}-Z_{t}^{N} \ln M_{i t+1}\right)+\left(\mu_{3, i, t+1}-\mu_{4, i, t+1}.\right)$

Hence, the risk premium of the noise traders depends upon the expectations of the market as a whole, augmented by a term which accounts for the disturbances due to their forecasting biases. Equations (12) and (15) define the risk premium for the two different categories of market participants. We note that a key feature of both these relationships is a term capturing the heterogeneity of the forecasting processes. Consensus, or average, measures of the risk premium may comprise both the smart and noise elements; however, access to disaggregate survey data should allow us to discover the importance of expectational differences. It is worth noting under what conditions this model reduces to that of Domowitz and Hakkio in which $E_{t} \ln S_{t+1}-\ln F_{t}=1 / 2\left[h_{33, t+1}-h_{44, t+1}\right]$. The conditions are that $\gamma_{11}=\gamma_{12}=\ldots . .=\gamma_{1}, \gamma_{21}=\gamma_{22}=\ldots \ldots . .=\gamma_{2}, \omega=1$ and that all agents hold rational expectations.

\section{ARCH models and survey based risk premium}

In this section we operationalise the model derived in section 3. In concern with Domowitz and Hakkio we generate the risk premium from the conditional variance of the forecast errors. Consistent with the previously developed model we allow heterogeneity to enter into the regression of conditional variance. The availability of the survey data allows us to examine not just a single strategy but instead the strategy of each of this firm for each currency. This research strategy allows us to gather much more evidence about the foreign exchange risk premium and the role of heterogeneity. In this case we define heterogeneity as the difference between the individual 's forecast and the average forecast. More specifically, we estimate an ARCH (1) -M multivariate model of the following form:

$\mathrm{s}_{\mathrm{i}, \mathrm{t}+1}-\mathrm{s}_{\mathrm{t}}=\lambda_{\mathrm{i}, \mathrm{t}}+\beta_{\mathrm{i}, 0}\left(\mathrm{f}_{\mathrm{t}}-\mathrm{s}_{\mathrm{t}}\right)+\varepsilon_{\mathrm{i}, \mathrm{t}+1}$

$\lambda_{\text {it }}=\alpha_{1}+\beta_{i, 1}+h_{i, t+1}$

$\varepsilon_{\mathrm{i}, \mathrm{t}+1} / \mathrm{I}_{\mathrm{t}} \sim \mathrm{N}\left(0, \mathrm{~h}_{\mathrm{t}+1}^{2}\right)$

$\mathrm{h}_{\mathrm{t}+1}^{2}=\gamma_{\mathrm{i}, 0}+\gamma_{\mathrm{i}, 1} \varepsilon_{\mathrm{i}, \mathrm{t}+1}^{2}+\gamma_{\mathrm{i}, 2}(\mathrm{Het})^{2}{ }_{\mathrm{t}+1}$

where the subscript $\imath$ denote the results of each firm.

Het stands for the heterogeneity and $I_{t}$ is the information set available to the investors at time $t$.

The availability of the survey data allows us to obtain a greater insight to each individual's forecasting behaviour. To the extent that we can detect regularities and common patterns among the individuals, in the following we provide a summary of these findings. The hope is that interesting information related to the forecasting behaviour can be identified. Before presenting the results of this analysis we should note that since the response rate is less than perfect, we constrain our ARCH analysis to a subset of the total panel examined in the first part of this work. Specifically, we fit an ARCH-M model in 51 for the DM, 46 for the BP, and 55 for the JY individuals consisting of banking sector and security industry.

The evidence seems to provide strong support for the theoretical model developed in the previous section. In particular for the DM there are 28 out of 34 cases in the banking sector and 13 out of 17 in the security industry in which the heterogeneity enters with a statistically significant coefficient. Similarly, for the case of BP the corresponding ratios are 22 out of 25 for banks and 19 out of 21 for the security industry, while for the JY 23 out of 28 for the bank 23 out of 27 for securities.

The high statistical significance of heterogeneity combined, in many cases, with the statistical insignificance of the other ARCH coefficients, suggest that the major part of the conditional volatility's momentum ${ }^{9}$ is explained solely by the heterogeneity. It seems that the heterogeneity mainly affects the forecasters based in UK while in the institutions based in France and Canada the heterogeneity is not statistically significant. Not surprisingly, in all cases, the heterogeneity enters with a positive sign, indicating that an increase in heterogeneity fits the conditional volatility and subsequently the risk premium. Overall, we could argue that the heterogeneity seems to affect similarly the forecasting patterns of both sectors. 
Table 8a

Results From The ARCH Model, Currency DM/Banks

\begin{tabular}{|c|c|c|c|c|}
\hline$\underline{\mathrm{V} 2}$ & $\underline{\mathrm{T} 2}$ & $\underline{\text { T1 }}$ & $+\mathrm{V} 2$ & -T1 \\
\hline$\overline{\mathrm{B} 13}$ & $\overline{\mathrm{B} 13}$ & & $\overline{\mathrm{B} 13}$ & $\overline{\mathrm{B} 13}$ \\
\hline B25 & & B25 & B25 & B25 \\
\hline B35 & & B35 & B35 & B35 \\
\hline $\mathrm{C} 1$ & & $\mathrm{C} 1$ & $\mathrm{C} 1$ & $\mathrm{C} 1$ \\
\hline C12 & $\mathrm{C} 12$ & C12 & $\mathrm{C} 12$ & $\mathrm{C} 12$ \\
\hline C15 & $\mathrm{C} 15$ & $\mathrm{C} 15$ & $\mathrm{C} 15$ & $\mathrm{C} 15$ \\
\hline \multirow[t]{2}{*}{$\mathrm{C} 2$} & & $\mathrm{C} 2$ & $\mathrm{C} 2$ & $\mathrm{C} 2$ \\
\hline & & & F10 & $\mathrm{F} 10$ \\
\hline F11 & & & F11 & F11 \\
\hline \multirow[t]{2}{*}{ F16 } & F16 & F16 & F16 & \\
\hline & F4 & & $\mathrm{F} 4$ & \\
\hline F9 & F9 & & F9 & \\
\hline G10 & G10 & & G10 & G10 \\
\hline G11 & & G11 & G11 & G11 \\
\hline G12 & G12 & G12 & G12 & G12 \\
\hline \multirow[t]{2}{*}{ G13 } & & & G13 & \\
\hline & G15 & G15 & & \\
\hline \multirow[t]{2}{*}{ G18 } & & G18 & G18 & G18 \\
\hline & G19 & & G19 & \\
\hline G2 & & G2 & G2 & G2 \\
\hline $\mathrm{G} 22$ & G22 & $\mathrm{G} 22$ & G22 & \\
\hline G23 & G23 & $\mathrm{G} 23$ & G23 & G23 \\
\hline G3 & & & G3 & G3 \\
\hline G4 & & & G4 & \\
\hline G5 & G5 & & G5 & G5 \\
\hline \multirow[t]{2}{*}{ G8 } & & G8 & G8 & \\
\hline & I1 & I1 & I1 & I1 \\
\hline I5 & I5 & & I5 & \\
\hline \multirow[t]{2}{*}{ I6 } & I6 & & I6 & \\
\hline & & & $\mathrm{J} 2$ & $\mathrm{~J} 2$ \\
\hline J9 & & & J9 & J9 \\
\hline U15 & U15 & U15 & U15 & U15 \\
\hline U19 & U19 & U19 & U19 & U19 \\
\hline U18 & $\mathrm{U} 18$ & U18 & U18 & U18 \\
\hline $82 \%$ & $56 \%$ & $56 \%$ & $97 \%$ & $68 \%$ \\
\hline
\end{tabular}

Total:34

Note: Under the column head V2 we present the cases having statistical significant the coefficient of heterogeneity. Under the column head T2 we present the cases having statistical significant the coefficient of the forward premium. Under the header $T 1$ we present the cases having statistical significant the coefficient of the risk premium. Under the column head $+V 2$ we present the cases having positive sign in the heterogeneity. Under the column head - T1 we present the cases having negative sign in the forward premium. 
Table 8b

Currency: Dm / Sec

$\underline{\text { V2 }}$

B18

B27

B29

B30

B4

B8

B9

C3

F12

F2

G5

J20

$\mathrm{J} 3$

$\mathbf{8 8 \%}$

Total:17

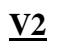

$\overline{\mathrm{B} 25}$

B13

C15

C1

F4

F12

F10

F5

F10

G10

G11

G12

G13

G2

G22

G3

G4

C5

G8

I1

I2

$\mathbf{8 8 \%}$

Total: 25
$\underline{\mathrm{T} 2}$

B18

B27

B29

B8

B9

C3

C4

F2

G5

J20

J3

$65 \%$

$\underline{12}$

G10

G4
T1

B18

B27

B29

B30

B9

C3

C4

F12

J20

U1

$59 \%$

Table 8c

Currency BP / Banks

$\underline{\mathrm{T} 1}$

B25

C15

C1

F12

F10

C5

F10

G11

G12

G2

G22

G4

G8

I2

$\mathrm{J} 2$

$60 \%$
$+\mathrm{V} 2$

B18

B27

B29

B30

B4

B8

B9

C3

C4

F12

F2

G5

J3

U1

U24

$\mathbf{8 8 \%}$
U24

$35 \%$

$\frac{-\mathbf{T 1}}{\mathrm{B} 18}$

B4

B8

C3

G5

-T1

B13

C15

C1

F4

C5

F5

G12

G13

G15

G22

G3

G4

G8

I1

I2

I5

$\mathrm{J} 2$

$68 \%$ 
Table 8d

Currency BP/Sec

\begin{tabular}{|c|c|c|c|c|}
\hline$\underline{\mathrm{V} 2}$ & $\underline{\mathbf{T} 2}$ & $\underline{\mathbf{T 1}}$ & $+\mathrm{V} 2$ & $\frac{-\mathbf{T 1}}{\mathrm{B} 30}$ \\
\hline$\overline{\mathrm{B} 30}$ & & $\overline{\mathrm{B} 30}$ & $\overline{\mathrm{B} 30}$ & $\overline{\mathrm{B} 30}$ \\
\hline B27 & & & B27 & B27 \\
\hline B22 & & & B22 & \\
\hline B2 & & B2 & B2 & \\
\hline B18 & & & B18 & B18 \\
\hline B14 & & B14 & B14 & B14 \\
\hline B12 & & & B12 & \\
\hline B9 & & B9 & B9 & B9 \\
\hline B8 & & B8 & B8 & B8 \\
\hline B4 & B4 & & B4 & B35 \\
\hline B35 & & B35 & B35 & \\
\hline $\mathrm{C} 18$ & & $\mathrm{C} 18$ & $\mathrm{C} 18$ & \\
\hline $\mathrm{C} 12$ & $\mathrm{C} 12$ & $\mathrm{C} 12$ & $\mathrm{C} 12$ & $\mathrm{C} 12$ \\
\hline \multirow[t]{2}{*}{ C4 } & $\mathrm{C} 4$ & & $\mathrm{C} 4$ & \\
\hline & G19 & & G19 & G19 \\
\hline G9 & & G9 & G9 & G9 \\
\hline I6 & & I6 & I6 & I6 \\
\hline $\mathrm{J} 20$ & & $\mathrm{~J} 20$ & $\mathrm{~J} 20$ & \\
\hline \multirow[t]{2}{*}{ U1 } & U1 & & U1 & U1 \\
\hline & & & U24 & U24 \\
\hline $95 \%$ & $25 \%$ & $52 \%$ & $100 \%$ & $70 \%$ \\
\hline
\end{tabular}

Table 8e

Currency: JY/Bank

V2

$\underline{\mathbf{T} 2}$

$\underline{\text { 1 }}$

$\frac{\mathbf{+ V 2}}{\mathrm{B} 13} \quad \frac{\mathbf{- T 1}}{\mathrm{B} 13}$

B25

B27

B13

B25

B27

B27

B25

B27

B9

F10

F16

F4

F5

F5

F5

G8

G4

G3

G20

G15

G12

G10

I1

I5

J9

J2

J17

J11

J13

82\%

Total:28

$\begin{array}{cccc} & & \text { B9 } & \\ & & \text { C1 } & \\ & & \text { F10 } & \\ \text { F5 } & \text { F16 } & \text { F16 } \\ & & \text { F5 } & \text { F5 } \\ & & \text { F9 } & \text { F9 } \\ & \text { G8 } & \text { G8 } & \text { G8 } \\ & & \text { G5 } & \\ & \text { G4 } & \text { G4 } & \text { G3 } \\ & & \text { G3 } & \\ & \text { G22 } & \text { G22 } & \\ \text { G12 } & \text { G15 } & \text { G13 } \\ \text { G10 } & \text { G13 } & \text { G12 } \\ \text { I1 } & \text { G12 } & \text { I1 } \\ \text { J9 } & & \text { I1 } & \text { I5 } \\ & & \text { I5 } & \text { J9 } \\ & & \text { J9 } & \text { J10 } \\ & & & \text { J17 } \\ & & \text { J17 } & \\ \mathbf{2 8 \%} & & \text { J11 } & \end{array}$




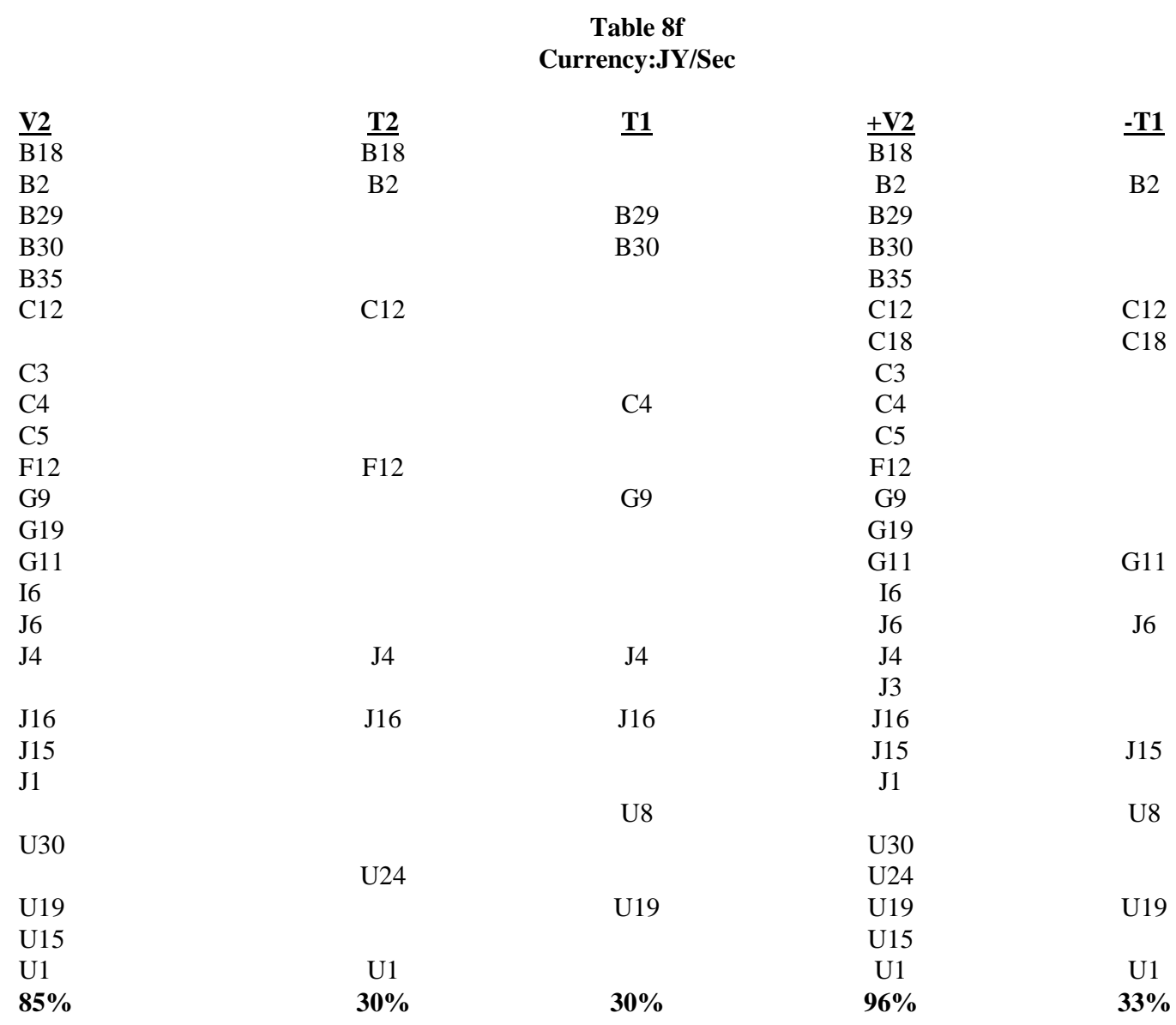

Total:27

Domowitz and Hakkio report rather weak results for the statistical significance of the risk premium in the unbiasedness equation. In our case the results present a rather mixed picture. In the case of DM and BP in a range 52-60 per cent of the cases the conditional variance is statistically significant. In contrast, the results are quite poor for JY in the sense that only 24 per cent in banks and 30 per cent in security industry produce conditional volatility different than zero. Evaluating the performance of sub-groups, it can be said that in the vast majority of the France-based institutions the risk premium is non different than zero, while the British-based institutions present weak results regarding the risk premium of the BP. Again, a notable indication arises from the almost identical influence of the risk premium in the forecasting patterns of the bank and security industry. The fluctuations between negative and positive values of the risk premium is in accordance with the findings of the Domowitz and Hakkio and the theoretical model proposed by Stockman (1978). The majority of the negative signs implies that the effect of the risk premium is to push estimates of the standard coefficient of $\beta$ above 1 . The positive indicates an overreaction to the information. The vast majority of positive signs is concentrated in the security industry ' $\mathrm{s}$ forecasting patterns, especially for the DM and the JY. For 67 per cent of individuals the risk premium of JY and $65 \mathrm{DM}$ enter with a positive sign, in the case of BP the ratio approaches 30 per cent.

\section{Conclusions}

In this paper we have examined some standard exchange rate expectational relationships using a disaggregate multicountry exchange rate survey database. The availability of survey data offers an independent measure of foreign exchange market participants' expectations of the exchange rate. The use of disaggregate data leads to conclusions which differ from the conclusion that would be drawn on the basis of the consensus forecasts. 
The presence of heterogeneous behavior combined with the existence of conditional heteroskedasticity in the forward forecast error prompted this work to develop a model of individual's risk premium. In contrast to the existing work on this area, instead of working with the representative individual agent we focus on the behavior of each individual. Having as building block the model derived by Domowitz and Hakkio we found that individual's risk premium is a function of the variables defined by the authors augmented by the heterogeneity of the market. By testing the derived model using the available data sets. It seems that the standard deviation derived from the multivariate ARCH-M(1,1) provide, for the most of the cases, an adequate explanation for the risk premium.

\section{Suggestions for Future Research}

The risk premium is a variable which represent the assign risk from each individual to the foreign exchange rate. Since the risk play a role in explaining the failure of forward premium to provide unbiased predictions the risk premium is a factor that carries the individual's forecasts away from the equilibrium value. The investigation of the individual's risk premium under the view of microstructure analysis can further support the fact that the risk premium is an important signaling variable (together with volume, volatility, heterogeneity and bid-ask spreads) in the formation of exchange rate expectation.

From the results provided, it seems that heterogeneity plays an important role in explaining foreign exchange changes and enters significantly into the risk premia equation. These findings are suggestive of the direction for building models based on individual behavior.

We thank the participants in the 3rd annual conference of European Financial Management Association Conference held in Athens (28/6-1/7/2000) for many helpful discussions.

\section{Endnotes}

1. The results are available from the author upon request.

2. This is also confirmed by a visual examination of the first 17 autocorrelation coefficients which show a slow decay of the ACF and lead us to the conclusion that the forward premium is a stationary series but in a strange way.

3. Dealing with the serial correlation we have to take into account the fact that the serial correlation would be more significant if we were taken into consideration the hypothesis done by Chinn and Frankel (1994). The authors argues that forecasters are reluctant to issue predictions of future rates that are similar as today 's rates

4. From the other side Hodrick (1987) points out that many economists are 'justifiably suspicious' of using survey data. The author supports this idea by using the arguments of Frankel and Froot (1985 p. 70)'...a cornerstone of positive economics is that we learn more by observing what people do (in the market place) than what they say.' Hodrick gives an example of a trader who possesses private information that he has used to construct a portfolio of positions based on the deviations of his expectations from the current forward rates. The question that arises is related to the tension of the trader to reveal his information when questioned.

5. This is the case for the Lucas (1982) and Domowitz and Hakkio models.

6. This part of the model is therefore similar to the model of Canova and Marrinan's (1993)

7. Relaxing this assumption would only unnecessarily complicate the model without adding any extra insight.

8. We use the Markov process here, even in the presence of non-rational expectations, as it does not significantly affect our final result.

9. We test for the existence of conditional heteroscedastic structure in the forecasting residuals by applying a LM test statistic. In the 97 per cent of the cases we can reject the null of no-conditional heteroscedasticity. 


\section{References}

1. Allen, H. L. and M. Talyor (1990), "Charts, noise and Fundamentals in the Foreign Exchange Market" Economic Journal, 100, 49-59.

2. Baillie, R. and T. Bollerslev (1990), "A multivariate Generalised ARCH Approach to modeling Risk Premia in Forward Foreign Exchange Rate Markets" Journal of International Money and Finance, 9, 309-324.

3. Campbell, J. and Clarida R. (1987), "The Term structure of Euromarket Interest Rates: An Empirical Investigation" Journal of Monetary Economics, 19, 25-44.

4. Canova, F. and J. Marrinan (1993), "Profits, Risk, and Uncertainty in foreign Exchange Markets" Journal of Monetary Economics, 32, 259-286.

5. Cavalia S., W. F.C. Verschoor, and C.Wolff (1993), "Further Evidence on Exchange Rate Expectations", Journal of International Money and Finance, 12,78-98.

6. Chionis, D. and R. MacDonald (1997):"Some tests of Market Microstructure Hypotheses in the Foreign Exchange Market" Journal of International Financial Management, vol 4.

7. Chinn, M. and J. Frankel (1994), " Patterns in Exchange Rate forecasts for Twenty-five Currencies" Journal of Money Credit and Banking, 26, 757-770.

8. Diebold , F. and P. Pauly (1987), "Endogeneous Risk in a Portfolio Balance Rational Expectations Model of the Deutschmark -Dollar Rate" European Economic Review,32, 27-53.

9. De Long J. B. A. Shleifer, L. Summers and R Waldmann (1990), "Noise Trade Risk in Financial Market" Journal of Political Economy, 98,703-739.

10. Dominguez, K (1986), "Are foreign Exchange forecasters Rational? New Evidence from Survey Data" Economics Letters 21, 277-281.

11. Domowitz I., and G. Hakkio (1985), "Conditional Variance and the risk Premium in the Foreign Exchange Market", Journal of International Economics, 19,47-66.

12. Engle, R. (1982), "Autoregressive Conditional Heteroskedasticity with estimates of the Variance of U.K. Inflation " Econometrica, 50, 987-1008.

13. Engle, R. and D. Lilien and R. Robins (1987), "Estimating Time Varying Risk Premia in Term Structure: The ARCH-M Model" Econometrica, 55, 391-407.

14. Engel, C. (1995), "The Forward Discount Anomaly and the Risk Premium: A Survey of Recent Evidence" National Bureau of Economic Research, Working Paper 5312.

15. Frankel J., and K. Froot (1990), "Exchange Rate Forecasting Techniques and Implications for the Foreign Exchange Markets", National Bureau of Economic Research, working Paper 3740.

16. Froot, K. and J. Frankel (1989), "Forward Discount Bias: is it an Exchange Rate Premium" Quarterly Journal of Economics, 139-161.

17. Hodrick, R. J. and S. Srivastava (1984), "An investigation of Risk and Return in Forward Foreign Exchange" Journal of International Money and Finance10, 335-360

18. Ito, T. (1990), "Foreign Exchange Rate Expectations: Micro Survey Data" American Economic Review, 80, 43439.

19. Kaminsky, C. and Peruga R. (1990), "Can a Time-Varying Risk Premium Explain Excess Returns in the Forward Market for Foreign Exchange?" Journal of International Economics, 28, 47-70.

20. Lee, K. (1988), " Does Conditional Covariance or Conditional Variance Explain Time Varying Risk Premia in Foreign Exchange Returns?" Economics Letters, 27,371-373.

21. Lucas R., (1982), "Interest Rates and Currency Prices in a Two-Country Model", Journal of Monetary Economics $10,335-360$.

22. MacDonald R.(1992), "Exchange Rate Survey Data: A Disaggregate G-7 Perspective" , The Manchester School LX Supplement, 47-62.

23. MacDonald R., and I. Marsh (1994), " Combining Exchange Rate Forecasts: What is the Optimal Consensus Measure?," Journal of Forecasting,13, 313-332.

24. MacDonald, R. and Torrance T. S. (1990), "Expectations Formation and Risk in Four Foreign Exchange Markets" Oxford Economic Papers, 42, 544-561.

25. McCurdy, T. and I. Morgan (1988), "Testing the Martingale Hypothesis in Deutsche Mark Futures with Models Specifying the Form of Heteroskedasticity" Journal of Applied Econometrics, 3, 187-202.

26. McCurdy, T. and I. Morgan (1987), "Tests of Martingale Hypothesis for Foreign Currency Futures with time Varying Volatility" International Journal of Forecasting, 3, 131-148. 


\footnotetext{
${ }^{1}$ The results are available form the author upon request

${ }^{2}$ This is also confirmed by a visual examination of the first 17 autocorrelation coefficients which show a slow decay of the ACF and lead us to the conclusion that the forward premium is a stationary series but in a strange way.

${ }^{3}$ Dealing with the serial correlation we have to take into account the fact that the serial correlation would be more significant if we were taken into consideration the hypothesis done by Chinn and Frankel (1994). The authors argues that forecasters are reluctant to issue predictions of future rates that are similar as today 's rates

${ }^{4}$ From the other side Hodrick (1987) points out that many economists are 'justifiably suspicious' of using survey data. The author supports this idea by using the arguments of Frankel and Froot (1985 p. 70)'...a cornerstone of positive economics is that we learn more by observing what people do (in the market place) than what they say.' Hodrick gives an example of a trader who possesses private information that he has used to construct a porfolio of positions based on the deviations of his expectations from the current forward rates. The question that arises is related to the tension of the trader to reveal his informnation when questioned.

${ }^{5}$ This is the case for the Lucas (1982) and Domowitz and Hakkio models.

${ }^{6}$ This part of the model is therefore similar to the model of Canova and Marrinan's (1993)

${ }^{7}$ Relaxing this assumption would only unecessarily complicate the model without adding any extra insight.

${ }^{8}$ We use the Markov process here, even in the presence of non-rational expectations, as it does not significantly affect our final result.

${ }^{9}$ We test for the existence of conditional heteroscedastic structure in the forecasting residuals by applying a LM test statistic. In the 97 per cent of the cases we can reject the null of no-conditional heteroscedasticity.
}

\section{References}

1. Allen, H. L. and M. Talyor (1990), "Charts, noise and Fundamentals in the Foreign Exchange Market" Economic Journal, 100, 49-59.

2. Baillie, R. and T. Bollerslev (1990), "A multivariate Generalised ARCH Approach to modeling Risk Premia in Forward Foreign Exchange Rate Markets" Journal of International Money and Finance, 9, 309324.

3. Campbell, J. and Clarida R. (1987), "The Term structure of Euromarket Interest Rates: An Empirical Investigation" Journal of Monetary Economics, 19, 25-44.

4. Canova, F. and J. Marrinan (1993), "Profits, Risk, and Uncertainty in foreign Exchange Markets" Journal of Monetary Economics, 32, 259-286.

5. Cavalia S., W. F.C. Verschoor, and C.Wolff (1993), " Further Evidence on Exchange Rate Expectations", Journal of International Money and Finance, 12,78-98. 
6. $\quad$ Chionis, D. and R. MacDonald (1997):"Some tests of Market Microstructure Hypotheses in the Foreign Exchange Market" Journal of International Financial Management, vol 4.

7. Chinn, M. and J. Frankel (1994), " Patterns in Exchange Rate forecasts for Twenty-five Currencies" Journal of Money Credit and Banking , 26, 757-770.

8. Diebold , F. and P. Pauly (1987), "Endogeneous Risk in a Portfolio Balance Rational Expectations Model of the Deutschmark -Dollar Rate" European Economic Review,32, 27-53.

9. De Long J. B. A. Shleifer, L. Summers and R Waldmann (1990), "Noise Trade Risk in Financial Market" Journal of Political Economy, 98,703-739.

10. Dominguez, K (1986), "Are foreign Exchange forecasters Rational? New Evidence from Survey Data" Economics Letters 21, 277-281.

11. Domowitz I., and G. Hakkio (1985), "Conditional Variance and the risk Premium in the Foreign Exchange Market", Journal of International Economics, 19,47-66.

12. Engle, R. (1982), "Autoregressive Conditional Heteroskedasticity with estimates of the Variance of U.K. Inflation " Econometrica, 50, 987-1008.

13. Engle, R. and D. Lilien and R. Robins (1987), "Estimating Time Varying Risk Premia in Term Structure: The ARCH-M Model" Econometrica, 55, 391-407.

14. Engel, C. (1995), "The Forward Discount Anomaly and the Risk Premium: A Survey of Recent Evidence" National Bureau of Economic Research, Working Paper 5312.

15. Frankel J., and K. Froot (1990), "Exchange Rate Forecasting Techniques and Implications for the Foreign Exchange Markets", National Bureau of Economic Research, working Paper 3740.

16. Froot, K. and J. Frankel (1989), "Forward Discount Bias: is it an Exchange Rate Premium" Quarterly Journal of Economics, 139-161.

17. Hodrick, R. J. and S. Srivastava (1984), "An investigation of Risk and Return in Forward Foreign Exchange" Journal of International Money and Finance10, 335-360

18. Ito, T. (1990), "Foreign Exchange Rate Expectations: Micro Survey Data" American Economic Review, 80, 434-39.

19. Kaminsky, C. and Peruga R. (1990), "Can a Time-Varying Risk Premium Explain Excess Returns in the Forward Market for Foreign Exchange?"Journal of International Economics, 28, 47-70.

20. Lee, K. (1988), " Does Conditional Covariance or Conditional Variance Explain Time Varying Risk Premia in Foreign Exchange Returns?" Economics Letters, 27,371-373.

21. Lucas R., (1982),"Interest Rates and Currency Prices in a Two-Country Model", Journal of Monetary Economics 10, 335-360.

22. MacDonald R.(1992), "Exchange Rate Survey Data: A Disaggregate G-7 Perspective" , The Manchester School LX Supplement, 47-62.

23. MacDonald R., and I. Marsh (1994), " Combining Exchange Rate Forecasts: What is the Optimal Consensus Measure?," Journal of Forecasting,13, 313-332.

24. MacDonald, R. and Torrance T. S. (1990), "Expectations Formation and Risk in Four Foreign Exchange Markets" Oxford Economic Papers, 42, 544-561.

25. McCurdy, T. and I. Morgan (1988), "Testing the Martingale Hypothesis in Deutsche Mark Futures with Models Specifying the Form of Heteroskedasticity" Journal of Applied Econometrics, 3, 187-202.

26. McCurdy, T. and I. Morgan (1987), "Tests of Martingale Hypothesis for Foreign Currency Futures with time Varying Volatility" International Journal of Forecasting, 3, 131-148. 